\title{
Perception and Practices of Colonoscopy Procedure: A Nationwide Survey of Indian Gastroenterologists
}

\author{
Jitendra Mohan Jha' Sethu Babu' \\ ${ }^{1}$ Department of Medical Gastroenterology, KIMS, Secunderabad, \\ Telangana, India
}

J Digest Endosc:2020;11:253-257

\begin{abstract}
Address for correspondence Jitendra Mohan Jha, Department of Medical Gastroenterology, KIMS, Secunderabad, Telangana, India (e-mail: jitendramohanjha@gmail.com).
\end{abstract}

\begin{abstract}
Keywords

- colonoscopy

- colon cancer

- screening

- survey
\end{abstract}

Introduction There is a lack of data and consensus about the practices and policies regarding performing colonoscopy in India. We surveyed gastroenterologists to assess their practices and policies of performing colonoscopy.

Methodology A questionnaire was presented to gastroenterologists all over India regarding their preference of bowel preparation and method of sedation, completeness of cecal and ileal intubation rates, preferences for inflation, use of carbon dioxide and nitrous oxide, and complications faced.

Results Of the 350 surveys, 307 had completely responded (88\%). Only $18 \%$ of the centers were conducting more than 100 colonoscopies a month and $46 \%$ denied following a colon cancer screening policy. Two bottles of liquid polyethylene glycol were the most preferred preparation. A total of $21 \%$ did not prefer any sedation at all. Nitrous oxide was used by only $5.6 \%$ of doctors. Ileal intubation rate was $>96 \%$ in $34 \%$ of centers and cecal intubation rate $>96 \%$ in $58 \%$ of centers. Air was used for inflation by $58 \%$, while $39 \%$ used $\mathrm{CO}_{2}$. A total of $40 \%$ of the respondents believe $\mathrm{CO}_{2}$ inflation would improve cecal intubation rate, while $9.4 \%$ believed otherwise. While one third found $\mathrm{CO}_{2}$ inflation unnecessary and $14 \%$ not cost-effective, three fourths were still interested in setting up a $\mathrm{CO}_{2}$ facility. Reasons for not using nitrous oxide were practical/administrative difficulty (46.6\%), side effects (20\%), and cost (16\%). Still more than half surveyed would consider using Entonox in future. Perforation was the most noted complication faced by respondents.

Conclusions This survey of real-world clinical practices will help to formulate practice guideline regarding colonoscopy in India.

\section{Introduction}

Colonoscopy is a widely used procedure in the endoscopy units in India. Since it is a painful procedure, it requires sedation. Propofol is a commonly used anesthetic agent, though many newer agents have been added in recent times. ${ }^{1}$ One of the most feared complication of colonoscopy is perforation. ${ }^{2}$ The choice of the anesthetic agent has been linked not only to the perforation rate ${ }^{3}$ but to the adenoma detection rate as well. ${ }^{4}$ In addition, technicalities like use of gas insufflation, preferred preparation, and time taken for the procedure have been reported to have varied effects on the colonoscopy-induced

DOI https://doi.org/

10.1055/s-0040-1721223 ISSN 0976-5042. pain and detection rates. ${ }^{5}$ Unfortunately, there is a lack of consensus about the practices and policies regarding performing colonoscopy in India. In addition, there is no survey that reflects the preferences and practices of colonoscopy centers in India. Obtaining such information will help us in determining the popular practices related to colonoscopy and reasons for them, which should help to formulate guidelines for performing safe and efficient routine colonoscopy procedures. We surveyed gastroenterologists to assess their practices and policies of performing colonoscopy in their day-to-day clinical gastroenterology practice.

\footnotetext{
(C) 2020. Society of Gastrointestinal Endoscopy of India.

This is an open access article published by Thieme under the terms of the Creative Commons Attribution-NonDerivative-NonCommercial-License, permitting copying and reproduction so long as the original work is given appropriate credit. Contents may not be used for commercial purposes, or adapted, remixed, transformed or built upon. (https://creativecommons.org/licenses/by-nc-nd/4.0/)

Thieme Medical and Scientific Publishers Pvt. Ltd., A-12, 2nd Floor, Sector 2, Noida-201301 UP, India
} 


\section{Methodology}

A survey assessing the current practices and perceptions toward colonoscopy was developed. The survey questionnaire was modified after an initial pilot study involving five gastroenterologists at our institution, thereby establishing internal validity of our survey. The questionnaire was then presented to 350 gastroenterologists all over India using standard print format. The gastroenterologists were initially explained the purpose thus avoiding opinion bias. A consent for participation in the survey and an abbreviated nonresponse form (for those who did not wish to participate in the full survey) were obtained. To maintain anonymity of the respondents, each survey was assigned a unique code and the responses remained anonymous to the study investigators. The survey comprised of a total of 15 questions of both closed ended and open-ended type. The respondents were able to select from one or more predefined answers or offer written responses. At the end of the survey, there was an opportunity to make further comments. The study was approved by the Institutional Ethics Committee.

The responses were coded in a spreadsheet (Microsoft Excel for Mac, version 15.12) and analyzed. Thematic analysis was used to assess written responses. Predefined responses were analyzed and tabulated.

\section{Results}

Of the 350 mailed surveys, 307 responded (88\%). Only $18 \%$ of the centers were conducting more than 100 colonoscopies a month and $46 \%$ denied following a policy of screening those above the age of 40 or 50 years for colon cancer (-Table 1). Approximately two-thirds of the surveyed gastroenterologists preferred two bottles of liquid polyethylene glycol (PEG) for preparation, while $26 \%$ preferred one pack of PEG powder and the remaining $11 \%$ preferred two bottles PEG as split preparation (-Table 2). Of the surveyed gastroenterologists, $21 \%$ preferred no sedation at all, while $19 \%$ preferred to sedate all their patients. Midazolam was the most commonly used sedative (49\%). Next most common was midazolam and fentanyl and $~ 11 \%$ preferred propofol. Sedation administered by an anesthesiologist was preferred by $59 \%$, while $22 \%$ preferred administering it themselves. Nitrous oxide was used by only $5.6 \%$

Table 1 Characteristics of the institution that participated in the survey

\begin{tabular}{|l|l|l|}
\hline $\begin{array}{l}\text { Number of colonoscopies/month } \\
\text { performed }\end{array}$ & Frequency & Percent \\
\hline Less than 50 & 130 & 42.3 \\
\hline $50-100$ & 121 & 39.4 \\
\hline $100-200$ & 27 & 8.8 \\
\hline $200-500$ & 29 & 9.4 \\
\hline $\begin{array}{l}\text { Do you have a policy that all people } \\
\text { above } 40 \text { or } \mathbf{5 0} \text { should be screened? }\end{array}$ & Frequency & Percent \\
\hline Yes & 164 & 53.4 \\
\hline No & 143 & 46.6 \\
\hline
\end{tabular}

of the surveyed gastroenterologists. Ileal intubation rate was more than $96 \%$ in $34 \%$ of centers and cecal intubation rate was more than $96 \%$ in $58 \%$ of centers (-Table 3 ). Less than $80 \%$ ileal and cecal intubation rates were reported by 4.2 and $3.9 \%$ of the centers, respectively. Mean time to complete the procedure was 10 to 20 minutes at $60 \%$ of the centers.

Air was used for inflation by $58 \%$, while $39 \%$ used $\mathrm{CO}_{2}$ (-Table 4). However, $40 \%$ of the respondents believe $\mathrm{CO}_{2}$ inflation would improve cecal intubation rate, and 9.4\% believed otherwise. Although one third found $\mathrm{CO}_{2}$ inflation unnecessary and $14 \%$ reported to be not cost-effective, three fourths were still interested in setting up a $\mathrm{CO}_{2}$ facility (-Table 5). Reasons for not using nitrous oxide were practical/administrative issues (46.6\%), side effects (20\%), and cost (16\%). Still, more than half of the surveyed would consider using Entonox in future. Perforation was the most common complication faced by respondents of the survey (66\%) (-Table 6). However, no one reported the incidence of perforation at their center. Other complications experienced by the respondents were post procedure pain $(6 \%)$, patient anxiety (3.3\%), bleeding (1\%), distension (0.3\%), improper bowel wash $(0.3 \%)$, and prolonged procedure $(0.3 \%)$.

Table 2 Distribution of responses according to the preference of preparation and sedation

\begin{tabular}{|l|l|l|}
\hline Preferred preparation & Frequency & Percent \\
\hline 1 Pack of polyethylene glycol powder & 80 & 26.1 \\
\hline 2 Bottles of liquid polyethylene glycol & 192 & 62.5 \\
\hline 2 Bottles of split prep & 35 & 11.4 \\
\hline Preference of sedation & Frequency & Percent \\
\hline No sedation & 66 & 21.5 \\
\hline As demands with pain & 61 & 19.9 \\
\hline Less than 50\% of the times & 79 & 25.7 \\
\hline More than 50\% of the times & 43 & 14 \\
\hline Always sedation & 58 & 18.9 \\
\hline Medication used for sedation & Frequency & Percent \\
\hline Midazolam & 151 & 49.2 \\
\hline Midazolam + Fentanyl & 74 & 24.1 \\
\hline Midazolam+pentazocine & 3 & 1 \\
\hline Midazolam+tramadol & 5 & 1.6 \\
\hline Midaz+butrom & 1 & 0.3 \\
\hline Nitrous oxide & 7 & 2.3 \\
\hline Nitrous oxide + IV sedation & 10 & 3.3 \\
\hline Propofol & 33 & 10.7 \\
\hline Any other(fentanyl) & 9 & 2.9 \\
\hline Not applicable & 14 & 4.6 \\
\hline Sedation/anesthesia administered by? & \\
\hline Anesthesiologist & 45 & 22.1 \\
\hline Gastroenterologist & \multicolumn{2}{|l|}{} \\
\hline Not applicable & 13 \\
\hline Nurse assistant & 68.7 \\
\hline
\end{tabular}


Table 3 Intubation rates and time taken for colonoscopy at different centers

\begin{tabular}{|l|l|l|}
\hline Ileal intubation rate & Frequency & Percent \\
\hline Less than 80 & 13 & 4.2 \\
\hline $81-85$ & 20 & 6.5 \\
\hline $86-90$ & 12 & 3.9 \\
\hline $91-95$ & 91 & 29.6 \\
\hline $96-100$ & 106 & 34.5 \\
\hline Not known & 65 & 21.2 \\
\hline Cecal intubation rate & Frequency & Percent \\
\hline Less than 80 & 12 & 3.9 \\
\hline $81-85$ & 17 & 5.5 \\
\hline $86-90$ & 8 & 2.6 \\
\hline $91-95$ & 58 & 18.9 \\
\hline $96-10$ & 178 & 58 \\
\hline Not known & 34 & 11.1 \\
\hline $\begin{array}{l}\text { Average time taken for completing } \\
\text { the procedure }\end{array}$ & Frequency & Percent \\
\hline Less than 10 min & 69 & 22.5 \\
\hline $10-20$ min & 185 & 60.3 \\
\hline More than 20 min & 53 & 17.3 \\
\hline
\end{tabular}

Table 4 Distribution of responses with respect to inflation during colonoscopy

\begin{tabular}{|c|c|c|}
\hline Used for inflation & Frequency & Percent \\
\hline Air & 171 & 55.7 \\
\hline $\mathrm{CO}_{2}$ & 120 & 39.1 \\
\hline $\mathrm{CO}_{2}+$ saline & 1 & 0.3 \\
\hline Saline & 15 & 4.9 \\
\hline $\begin{array}{l}\text { Does } \mathrm{CO}_{2} \text { improve cecal intuba- } \\
\text { tion rate? }\end{array}$ & Frequency & Percent \\
\hline No & 29 & 9.4 \\
\hline Not cost-effective & 43 & 14 \\
\hline Not required & 113 & 36.8 \\
\hline Yes & 122 & 39.7 \\
\hline Patient reported discomfort & Frequency & Percent \\
\hline Less with $\mathrm{CO}_{2}$ gas + sedation & 1 & 0.3 \\
\hline Less with $\mathrm{CO}_{2}$ gas alone & 107 & 34.9 \\
\hline Less with Entonox & 10 & 3.3 \\
\hline Less with IV medication & 120 & 39.1 \\
\hline $\begin{array}{l}\text { Less with no sedation or no } \\
\mathrm{CO}_{2} \text { inflation }\end{array}$ & 23 & 7.5 \\
\hline Not applicable & 5 & 1.6 \\
\hline Similar with/without $\mathrm{CO}_{2}$ & 40 & 13 \\
\hline Yes with IV medication & 1 & 0.3 \\
\hline
\end{tabular}

\section{Discussion}

Thepresent study is a first of its kind, which was conducted to understand the clinical practices and perceptions of gastroenterologists across India toward colonoscopy of the surveyed, $21 \%$ preferred no sedation at all, while $19 \%$
Table 5 Distribution of responses according to the use of $\mathrm{CO}_{2}$ and $\mathrm{N}_{2} \mathrm{O}$

\begin{tabular}{|l|l|l|}
\hline Interested in setting up $\mathrm{CO}_{2}$ facility & Frequency & Percent \\
\hline Already have & 4 & 1.3 \\
\hline No & 75 & 24.4 \\
\hline Yes & 228 & 74.3 \\
\hline $\begin{array}{l}\text { Why nitrous oxide is not used rou- } \\
\text { tinely in your center? }\end{array}$ & Frequency & Percent \\
\hline Cost & 49 & 16 \\
\hline Current success rate high & 42 & 13.7 \\
\hline Not aware & 1 & 0.3 \\
\hline Practical difficulty & 143 & 46.6 \\
\hline Side effects & 62 & 20.2 \\
\hline All of the above & 1 & 0.3 \\
\hline Others (cannot comment) & 9 & 2.9 \\
\hline Would consider using Entonox & Frequency & Percent \\
\hline Yes & 160 & 52.1 \\
\hline No & 147 & 47.9 \\
\hline
\end{tabular}

Table 6 Distribution of responses according to the complication reported

\begin{tabular}{|l|l|l|}
\hline Complications if any & Frequency & Percent \\
\hline Bleeding & 3 & 1 \\
\hline Distension & 1 & 0.3 \\
\hline Improper bowel wash & 1 & 0.3 \\
\hline None & 70 & 22.8 \\
\hline $\begin{array}{l}\text { Patient anxiety requiring } \\
\text { counselling }\end{array}$ & 10 & 3.3 \\
\hline Perforation & 203 & 66.1 \\
\hline Post procedure pain & 18 & 5.9 \\
\hline Prolonged time during procedure & 1 & 0.3 \\
\hline Total & 307 & 100 \\
\hline
\end{tabular}

preferred to sedate all their patients, midazolam being the most commonly used sedative. This proportion is relatively low from what has been reported from other parts of the world. In a survey of members of the Canadian Association of Gastroenterology and members of the Canadian Society of Colon and Rectal Surgeons, most endoscopists reported using sedation for more than $90 \%$ of colonoscopies, the most common sedation regimen being a combination of midazolam and fentanyl. ${ }^{6}$ More than $80 \%$ of the respondents in the their survey used a combination of a benzodiazepine and a narcotic, of which midazolam and fentanyl were most preferred. This pattern is similar to that reported in the United States, where more than $98 \%$ of colonoscopies are performed with intravenous sedation and more than three-quarters use midazolam and fentanyl. ${ }^{7}$ Approximately two-thirds of Swiss gastroenterologists also reported to use sedation for colonoscopy for more than $75 \%$ of cases. ${ }^{8}$ However, countries such as Japan and Italy have pursued unsedated colonoscopy with great success. ${ }^{9}$ Some experts feel that experienced 
endoscopists are likely to succeed in unsedated colonoscopies as they can maneuver the colon without causing pain and discomfort to patients. Furthermore, only 5.6\% of our surveyed gastroenterologists used nitrous oxide with or without sedation. A double-blind, randomized, placebo-controlled trial found that the patient-reported pain was similar in the group receiving nitrous oxide and in the control group. ${ }^{10}$ Also, patients in the nitrous oxide group received intravenous sedatives and analgesics equally often and in similar doses. In a study comparing administration of continuous 50\% nitrous oxide and patient-maintained, target-controlled propofol, Maslekar et $\mathrm{al}^{11}$ found similar patient satisfaction and analgesic and sedative effects in the two groups. The conflicting evidence might be explained by the different methods of nitrous oxide administration (continuous versus on demand).

From our survey, it was reported that cecal intubation rate was more than $96 \%$ in $58 \%$ of centers. Level and type of training can affect the endoscopist performance and it has been shown that poor cecum intubation rate is correlated to increased risk of postcolonoscopy colorectal cancer. ${ }^{12}$ Some guidelines differentiate between minimum standards for cecal intubation rate, depending on whether it is in screening $(95 \%)$ or clinics $(90 \%){ }^{13}$ European guidelines do not differentiate between the indication for colonoscopy and recommend $90 \%$ intubation rates for all cases..$^{14}$ Unfortunately, such guidelines are missing in India and a need for developing a consensus about colonoscopy quality indicators among Indian gastroenterologists is needed.

The use of $\mathrm{CO}_{2}$ was initially proposed by Becker in 1953, but endoscopists began to consider $\mathrm{CO}_{2}$ insufflation to reduce postprocedure pain in 1980s..$^{15}$ In our survey, air was used for inflation by $58 \%$, while $39 \%$ used $\mathrm{CO}_{2}$. However, $40 \%$ of the respondents believe $\mathrm{CO}_{2}$ inflation would improve cecal intubation rate, and $9.4 \%$ believed otherwise. A recent meta-analysis evaluated the effectiveness of $\mathrm{CO}_{2}$ insufflation for colonoscopy and compared with conventional air insufflation. ${ }^{16}$ The authors found that $\mathrm{CO}_{2}$ insufflation resulted in reduced procedural pain and also postprocedural pain at 1 hour and 6 and 24 hours. $\mathrm{CO}_{2}$ insufflation was also associated with faster cecal intubation but the cecal intubation rate was similar in both colonic insufflation techniques suggesting individual expertise as the success factor.

Role of nitrous oxide in obstetric and dental practice is long established, but its introduction into colonoscopy practice has occurred relatively recently. Lindblom et al are the first ones to conduct randomized studies describing the use of Entonox (50:50 combination of nitrous oxide and oxygen that is inhaled using a demand valve) during colonoscopy. ${ }^{17}$ Cochrane review has deemed Entonox to be safe, well tolerated, and reducing discharge times compared with intravenous sedatives. ${ }^{18}$ Our survey revealed a very low utilization rate of nitrous oxide among gastroenterologists for colonoscopy and reasons for not using nitrous oxide included practical/administrative issues (46.6\%), side effects (20\%), and cost (16\%). Still, more than half of the surveyed centers considered using Entonox in future. A survey of colonoscopists within the English Bowel Cancer Screening Program revealed that although Entonox was available to 74.5\%, only $47.3 \%$ of respondents used Entonox during $20 \%$ of procedures. ${ }^{19}$ Respondents avoided using Entonox in females, patients with high anxiety, and previous abdominal surgery. Of the 25.5\% respondents for whom Entonox was not available, $38.4 \%$ indicated that this was due to practical difficulties, 28.8\% due to being satisfied with current analgesics and sedation, $13.4 \%$ due to cost, $11.5 \%$ did not consider Entonox, $3.8 \%$ due to lack of efficacy, and $1.9 \%$ due to side effects.

Our survey respondents reported perforation to be the most common complication. This survey could not decide the real incidence perforation as it needs a direct question and further study on the outcome of perforation. Other complications experienced by the respondents were postprocedure pain, patient anxiety, and bleeding. Kim et al reviewed recent literature and found the perforation rate to range from 0.005 to $0.085 \%$ (as reported in large studies $\geq 50,000$ colonoscopies) ${ }^{20}$ The trend in the overall perforation rate in the past 15 years has not changed significantly. However, bleeding is a more common adverse event than perforation as recent large studies ( $\geq 50,000$ colonoscopies) have reported postcolonoscopy bleeding occurring in 0.001 to $0.687 \%$ of cases.

There are a few limitations of this study. First, even with a high response rate (88\%), it being survey based, the results are prone to nonresponse bias. The number of professionals surveyed is very small but the study has given an idea to formulate a larger group for better understanding and recommendations. Second, all surveys are subject to recall bias, as documentary evidence for various responses was not sought. Finally, the original study design was descriptive in nature and comparisons among groups were not prespecified. So, posthoc comparative analysis was not performed based on the level of training and years of experience of the respondent and the geographical location of the center and its characteristics (level of care, private vs. government). It is also possible a high-volume center or low-expertise professionals could make significant change. The current study is regarding the practice of sedation, bowel preparation, and the gas used for insufflation among a selected group of gastroenterologists who responded to the survey. Other outcomes such as cecal/ ileal intubation rates, procedure duration, and complications are highly prone to recall bias.

Participants were chosen randomly and not zone-wise. It included gastroenterologists working at tertiary care center and teaching in hospitals. Almost 10\% gastroenterologists in India were surveyed. It is a limitation that we did not include each one.

\section{Conclusion}

The success of colonoscopy procedure has significantly increased the detection of various colonic diseases in Indian gastroenterology practice and also played a key role in early detection of colorectal cancer, and helped early and successful surgery. Our survey of real-world clinical practices highlights the preferences of gastroenterologists from across 
India while conducting colonoscopies. It is hoped that this data will help to formulate practice guideline for a successful and safe colonoscopy in India.

\section{Conflict of Interest}

None.

\section{References}

1 Wernli KJ, Brenner AT, Rutter CM, Inadomi JM. Risks associated with anesthesia services during colonoscopy. Gastroenterology 2016;150(4):888-894, quiz e18

2 Lüning TH, Keemers-Gels ME, Barendregt WB, Tan AC, Rosman C. Colonoscopic perforations: a review of 30,366 patients. Surg Endosc 2007;21(6):994-997

3 Adeyemo A, Bannazadeh M, Riggs T, Shellnut J, Barkel D, Wasvary H. Does sedation type affect colonoscopy perforation rates? Dis Colon Rectum 2014;57(1):110-114

4 Katherine MH, Jennifer LH, Glenn ME. More large polyps are seen on screening colonoscopy with deep sedation compared with moderate conscious sedation. Gastrointest Endosc 2009;69:AB119-AB20

5 Falt P, Liberda M, Smajstrla V, et al. Combination of water immersion and carbon dioxide insufflation for minimal sedation colonoscopy: a prospective, randomized, single-center trial. Eur J Gastroenterol Hepatol 2012;24(8):971-977

6 Porostocky P, Chiba N, Colacino P, Sadowski D, Singh H. A survey of sedation practices for colonoscopy in Canada. Can J Gastroenterol 2011;25(5):255-260

7 Cohen LB, Wecsler JS, Gaetano JN, et al. Endoscopic sedation in the United States: results from a nationwide survey. Am J Gastroenterol 2006;101(5):967-974

8 Heuss LT, Froehlich F, Beglinger C. Changing patterns of sedation and monitoring practice during endoscopy: results of a nationwide survey in Switzerland. Endoscopy 2005;37(2):161-166

9 Leung FW, Aljebreen AM, Brocchi E, et al. Sedation-risk-free colonoscopy for minimizing the burden of colorectal cancer screening. World J Gastrointest Endosc 2010;2(3):81-89
10 Løberg M, Furholm S, Hoff I, Aabakken L, Hoff G, Bretthauer M. Nitrous oxide for analgesia in colonoscopy without sedation. Gastrointest Endosc 2011;74(6):1347-1353

11 Maslekar S, Balaji P, Gardiner A, Culbert B, Monson JR, Duthie GS. Randomized controlled trial of patient-controlled sedation for colonoscopy: Entonox vs modified patientmaintained target-controlled propofol. Colorectal Dis 2011; 13(1):48-57

12 Baxter NN, Sutradhar R, Forbes SS, Paszat LF, Saskin R, Rabeneck L. Analysis of administrative data finds endoscopist quality measures associated with postcolonoscopy colorectal cancer. Gastroenterology 2011;140(1, Suppl. 40) :65-72

13 Rex DK, Schoenfeld PS, Cohen J, et al. Quality indicators for colonoscopy. Gastrointest Endosc 2015;81(1):31-53

14 von Karsa L, Patnick J, Segnan N, et al; European Colorectal Cancer Screening Guidelines Working Group. European guidelines for quality assurance in colorectal cancer screening and diagnosis: overview and introduction to the full supplement publication. Endoscopy 2013;45(1):51-59

15 Hussein AM, Bartram CI, Williams CB. Carbon dioxide insufflation for more comfortable colonoscopy. Gastrointest Endosc 1984;30(2):68-70

16 Sajid MS, Caswell J, Bhatti MI, Sains P, Baig MK, Miles WF. Carbon dioxide insufflation vs conventional air insufflation for colonoscopy: a systematic review and meta-analysis of published randomized controlled trials. Colorectal Dis 2015; 17(2):111-123

17 Lindblom A, Jansson O, Jeppsson B, Törnebrandt K, Benoni C, Hedenbro JL. Nitrous oxide for colonoscopy discomfort: a randomized double-blind study. Endoscopy 1994;26(3):283-286

18 Aboumarzouk OM, Agarwal T, Syed Nong Chek SA, Milewski PJ, Nelson RL. Nitrous oxide for colonoscopy. Cochrane Database Syst Rev 2011;(8):CD008506

19 Ball AJ, Campbell JA, Riley SA. Nitrous oxide use during colonoscopy: a national survey of English screening colonoscopists. Frontline Gastroenterol 2014;5(4):254-259

20 Kim SY, Kim HS, Park HJ. Adverse events related to colonoscopy: Global trends and future challenges. World J Gastroenterol 2019;25(2):190-204 